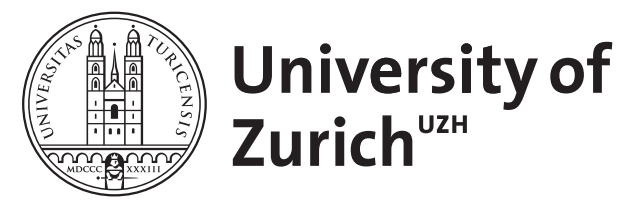

\title{
Word accent and mapping rules in Yurakaré
}

\author{
Van Gijn, Rik
}

\begin{abstract}
This paper looks in detail at stress assignment in the Bolivian isolate language Yurakaré, one of the few processes in the language that require the phonological-word ( $p$-word) as its domain of application. In terms of stress assignment, the p-word in Yurakaré interacts not only with the morphological component, but also with the syntactic component. Moreover, morphological interference with the prosodic component seems to start below the level of the p-word. I argue that these complex, conditional mappings can be thought of as either structurally conditioned diachronic remnants of grammaticalized items or as functionally motivated peculiarities.
\end{abstract}

DOI: https://doi.org/10.1007/s11525-014-9238-8

Posted at the Zurich Open Repository and Archive, University of Zurich ZORA URL: https://doi.org/10.5167/uzh-99716

Journal Article

Published Version

Originally published at:

Van Gijn, Rik (2014). Word accent and mapping rules in Yurakaré. Morphology, 24(3):223-244.

DOI: https://doi.org/10.1007/s11525-014-9238-8 


\title{
Word accent and mapping rules in Yurakaré
}

\author{
Rik van Gijn
}

Received: 20 March 2014 / Accepted: 17 July 2014 / Published online: 21 August 2014

(C) Springer Science+Business Media Dordrecht 2014

\begin{abstract}
This paper looks in detail at stress assignment in the Bolivian isolate language Yurakaré, one of the few processes in the language that require the phonological-word (p-word) as its domain of application. In terms of stress assignment, the p-word in Yurakaré interacts not only with the morphological component, but also with the syntactic component. Moreover, morphological interference with the prosodic component seems to start below the level of the p-word. I argue that these complex, conditional mappings can be thought of as either structurally conditioned diachronic remnants of grammaticalized items or as functionally motivated peculiarities.
\end{abstract}

Keywords Yurakaré · Phonological word · Prosodic hierarchy $\cdot$ Mapping rules · Accent

\section{Introduction}

Since the publication of Dixon (1977) an increasing number of scholars have argued for the need to recognize a phonological word (p-word) separately from the grammatical word (g-word), based on the domain of application of particular prosodic

\footnotetext{
${ }^{1}$ This depends to some extent on your theory. Nespor and Vogel (1986) deny the possibility of a p-word that contains more than one g-word. However, empirical evidence suggest that clitics can in fact be part of a larger p-word (cf. e.g. Revithiadou 2011).
}

My thanks go out to the speakers of Yurakaré for their patience and generosity in sharing their language with me. I furthermore thank Kristine Hildebrandt, Norval Smith, Fernando Zúñiga, Geert Booij, and an anonymous reviewer for discussions of the data and valuable suggestions for improvement. I also thank NWO, the DoBeS Foundation, and the SNSF for their financial support.

R. van Gijn (

Dept. of comparative linguistics, University of Zürich, Plattenstrasse 54, 8032 Zürich, Switzerland e-mail: erik.vangijn@uzh.ch 
Fig. 1 The prosodic hierarchy and assumed mapping relations (Hall et al. 2008)

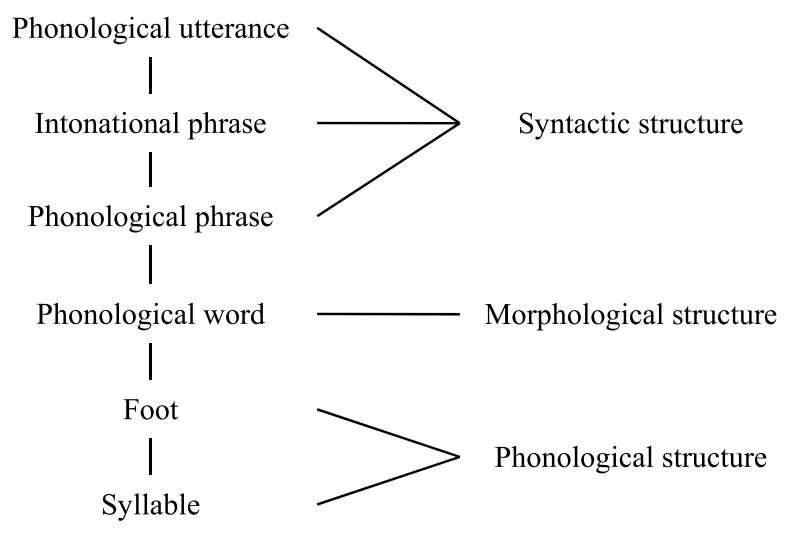

and phonological rules. It has been shown repeatedly and for several different languages that p-words and g-words may but need not coincide. A g-word can contain more than one p-word (the case defended by Dixon 1977 for Yidiny) or a p-word can contain more than one g-word (e.g. in the case of clitics). ${ }^{1}$ Apart from p-words and g-words, there are mapping rules or constraints connect the prosodic components to non-phonological domains of language.

The p-word is furthermore often assumed to stand in a hierarchical relation with other prosodic components (the prosodic hierarchy, see Selkirk 1978, 1980; Nespor and Vogel 1986). Each of these prosodic domains is associated with their particular set of mapping rules. Figure 1 shows a fairly generally accepted version of the prosodic hierarchy to the left, and the assumed relations with non-prosodic information (taken from Hall et al. 2008:184). ${ }^{2}$ As can be seen, the mappings are assumed to be purely phonological until the level of the p-word, "the lowest constituent of the prosodic hierarchy which is constructed on the basis of mapping rules that make substantial use of information from non-phonological domains" (Nespor and Vogel 1986:107).

The idea of the mapping relations is twofold:

i. A prosodic constituent is connected to a constituent from the corresponding language module to the right. This correspondence by no means needs to be perfect, but there is at least some overlap and it needs to be consistent.

ii. In order for the phonological rules to apply correctly and consistently within the prosodic domain, the prosodic module has to have access to specific information from the nonphonological modules.

Two recent papers, Bickel et al. (2009) and Schiering et al. (2010), criticize some of the universalist assumptions of the model displayed in Fig. 1. Bickel et al. (2009) argue on the basis of cross-linguistic evidence that phonological rules that apply to domains larger than the foot and smaller than the Phonological Phrase, rather than

\footnotetext{
${ }^{2}$ This is a simplified picture. It is generally also assumed that especially the higher prosodic constituents interact with semantics and pragmatics. Moreover, some theorists argue for more prosodic domains than the ones represented in Fig. 1. Perhaps most notably Nespor and Vogel (1986) and Vogel (1990, 2009) defend the clitic group as a prosodic constituent, consisting of the p-word plus clitics that attach to it.
} 
converging on a single prosodic domain which can be termed the p-word, tend to apply to domains of different extensions. This suggests a much richer structure than is suggested by the Prosodic Hierarchy. Interestingly, they do recognize a clear trend in the data: "stress-defined domains tend to be significantly larger than other domains" (Ibid. p. 72).

Schiering et al. (2010) additionally discuss data which show that there are languages like Vietnamese, which seem to have no necessity for a p-word domain. This leads the authors to the conclusion that "the 'word' has no privileged or universal status in phonology, but only emerges through frequent reference of sound patterns to a given construction type in a given language."

In this paper, I investigate the most important criterion for p-wordhood in the Bolivian isolate language Yurakaré, namely word stress, and the intricate ways in which its assignment interacts with other modules of grammar, at some points going beyond the generally assumed mapping relations. I will furthermore suggest that these mappings can be thought of as either diachronic remnants of grammaticalized items (in support of Schiering et al.'s 2010 dynamic perspective of the word) or as functionally motivated peculiarities.

The paper is structured as follows. Section 2 introduces the Yurakaré language and some of its most salient characteristics. Section 3, which makes up the bulk of the paper, discusses word accent in Yurakaré and its interactions with prosodic nonprosodic domains of language. In particular, the special behaviour of certain prefixes and a handful of roots in relation to stress placement, the deviant behaviour of nominal roots with respect to footing, and the inconsistent behavior of clitics. Section 4 discusses the results by addressing potential explanations for the facts of Yurakaré and Sect. 5 concludes the paper.

\section{The Yurakaré language}

Yurakaré is spoken in Central Bolivia, in the north-eastern parts of the department of Cochabamba and the south-eastern parts of the department of the Beni. The approximate geographical boundaries of the habitat of the Yurakaré are marked by rivers (Isiboro and Sécure Rivers in the North, Mamoré and Chimoré Rivers in the East) and the Andean foothills in the South and West. This area measures about 30,000 square kilometers, and contains many rivers, along which the Yurakaré live in small and scattered communities. Other ethnic groups that live here or in adjacent areas are Bolivian Quechua [QUEChuan], Chimane [Mosetenan], Yuki [TuPIAN], and Trinitario [ARAWAKAN]. There is contact with all of these groups, but not many obvious traces of this can be found in the language.

Yurakaré is commonly regarded as an isolate language, even though a number of scholars have proposed genealogical links for the language. For instance, Swadesh (1962) classifies Yurakaré in the Macro-Quechuan network, together with, among others, neighbouring Quechuan and Mosetenan languages. Greenberg (1987) considers Yurakaré to be in the Andean-Equatorial stock (with e.g. Tupian and Arawak languages), and Suárez (1974) has proposed a link with Chon, Mosetenan, Panoan, and Tacanan languages (Macro-Pano-Tacanan). Neither of these proposals is convincing, 
Table 1 Consonants and their graphs

\begin{tabular}{llllllllllllllllllll}
\hline IPA symbol & $\mathrm{p}$ & $\mathrm{t}$ & $\mathrm{t} \int$ & $\mathrm{k}$ & $\mathrm{P}$ & $\mathrm{b}$ & $\mathrm{d}$ & $\mathrm{d} j$ & $\mathrm{~s}$ & $\int$ & $\mathrm{h}$ & $\mathrm{I}$ & $\mathrm{m}$ & $\mathrm{n}$ & $\mathrm{y}$ & 1 & $\mathrm{w}$ & $\mathrm{j}$ \\
Orthography & $\mathrm{p}$ & $\mathrm{t}$ & $\mathrm{ch}$ & $\mathrm{k}$ & $\bullet$ & $\mathrm{b}$ & $\mathrm{d}$ & $\mathrm{dy}$ & $\mathrm{s}$ & $\mathrm{sh}$ & $\mathrm{j}$ & $\mathrm{r}$ & $\mathrm{m}$ & $\mathrm{n}$ & $\tilde{\mathrm{n}}$ & $\mathrm{l}$ & $\mathrm{w}$ & $\mathrm{y}$ \\
\hline
\end{tabular}

Table 2 Vowels and their graphs

\begin{tabular}{llllllll}
\hline IPA symbol & $\mathrm{i}$ & $\mathrm{i}$ & $\mathrm{u}$ & $\mathrm{e}$ & $\mathrm{o}$ & $\mathfrak{x}$ & $\mathrm{a}$ \\
Orthography & $\mathrm{i}$ & $\ddot{\mathrm{i}}$ & $\mathrm{u}$ & $\mathrm{e}$ & $\mathrm{o}$ & $\ddot{\mathrm{e}}$ & $\mathrm{a}$ \\
\hline
\end{tabular}

however, as they are often based on scanty data and generated by methods (glottochronology, mass comparison) that are today considered unreliable in themselves by a large part of the linguistic audience (cf. e.g. Campbell 1997; McMahon and McMahon 2005). It is striking, nevertheless, that even in these lumping approaches, Yurakaré generally turns up somewhere on the periphery of the proposed grouping, without any near relatives. The term isolate may therefore be more accurate than unclassified.

In spite of its relatively healthy number of speakers (especially compared to some other languages of the area), the language is endangered. This status is mainly due to the fact that the youngest generation (ca. 20 and younger) often has at most a passive knowledge of the language. Ancient traditions and rituals, to do with shamanism, mourning, initiation, etc. have been largely lost, and Spanish is rapidly taking over in more and more domains.

Yurakaré has a phoneme inventory that consists of 18 consonants and 7 vowels, a (C) V(C) syllable structure, with some constraints on possible coda consonants. There are few morphophonological processes, but elision of unstressed vowels is common (see Sect. 3.3 below). The phoneme inventories with the corresponding graphemes are given in Tables 1 and 2. All consonants, except the glottal stop, have geminate counterparts, but geminate consonants are not phonemic.

In terms of its verbal morphology, Yurakare is on the high end of the synthetic scale with at maximum of three pronominal affixes on the verb and a system of applicatives marking different semantic types of object (see Van Gijn 2011a, 2011b for more information). Productive compounding is limited to endocentric and exocentric noun-noun compounds; there is no noun incorporation into verbs. The non-verbal word classes are much less synthetic, although nouns do have some morphology associated with them, like possessive pronominal prefixes. The language has a clear preference for concatenative morphology; both nouns and verbs have prefixes as well as suffixes. There are also a number of clitics (see Sect. 3.4 below). In terms of relational marking, Yurakaré is predominantly head-marking (Van Gijn 2005).

In terms of its syntax, Yurakaré has a pragmatically determined main-clause word order, which is basically V-initial, with an open first position. Core arguments are indexed on the verb so they may be, and usually are, left unexpressed. A system of switch reference that is sensitive to event integration (Van Gijn 2011c) characterizes different types of complex clauses (complementation, relative clauses and adverbial clauses). 


\section{Stress and prosody-morphology interactions in Yurakaré}

\subsection{Stress assignment: basic rules}

Yurakaré has a so-called morphological accent system, in which "surface stress is the result of a complex interplay of stem type (accented versus unaccented) and diacritic properties of affixes" (Hayes 1995:32). Yurakaré has a default rhythmic pattern (iambic left-to-right with weight sensitivity), but a number of often morphemespecific rules that influence this basic pattern. The intimate connection between metrics and morphological structure raises questions about how the p-word relates to the g-word ${ }^{3}$ and its morphological structure.

In the next sections I discuss several aspects that relate to rhythm and stress in Yurakare which demonstrate the intricacies of the connections between grammatical and phonological structures in this language, calling for a more complex picture than the one given in Fig. 1 above. Before going into these issues, however, I briefly outline the basics of the Yurakaré stress system.

If we disregard lexical and pragmatic interference with stress-placement (I come back to these below), the system can be readily described by four parameters: a basic rhythmic pattern, weight sensitivity, extrametricality of the final syllable, and a rightmost primary stress placement. The underlying rhythmic pattern of Yurakaré accentuation is iambic. ${ }^{4}$ Combined with the additional constraint that word-final syllables are extrametrical these rules account for the accent pattern of the following words. ${ }^{5}$ The different lines in $(1 \mathrm{a}-\mathrm{c})$ correspond, from top to bottom, to the phonetic transcription, an orthographic rendering of the g-word with morpheme breaks indicated, the prosodic structure, and finally a translation. Unless indicated otherwise, this will be the basic structure of the examples.

$$
\begin{array}{ll}
\text { a. } & \text { 'mala] } \\
& \text { mala } \\
& \left((\mathrm{ma} .)_{\mathrm{FT}}<\mathrm{la}>\right)_{\mathrm{Pw}} \\
& \text { 'He went away.' }
\end{array}
$$

\footnotetext{
${ }^{3} \mathrm{G}$-words in Yurakare cannot be interrupted by other lexical material and strings of affixes—other than strings of words-obey rigid ordering principles, though there are a few exceptions. Since Yurakaré has synthetic morphological structure with bound pronominal affixes for subject participants and at most two object participants, g-words can at the same time function as sentences. This is true for verbs, but also for nouns and adjectives, which can function as predicates without any overt derivational marking, as can be seen in e.g. (1c).

${ }^{4}$ Although there are alternative ways to analyse the data in (1) it will become clear in the course of the paper that an iambic pattern is the only rhythmic pattern that accounts best for the facts of Yurakaré prosody.

${ }^{5}$ Throughout this paper, grammatical words (g-words) are rendered as an uninterrupted string of orthographic symbols. When two or more g-words are part of the same phonological word, or if one g-word adjoins to another without projecting its own p-word, they are separated by the symbol '='; if they belong to different phonological words, they are separated by a space. Following official Yurakaré spelling, primary stress is indicated only when it does not fall on the penultimate syllable. Where relevant, I will give the prosodic structure of p-words, where feet and phonological words are represented between (round brackets) and with subscripts and extrametrical syllables between $<$ fish hooks $>$. Syllable boundaries are given where relevant by a period following the syllable.
} 
b. [po'hose]

pojore

$\left((\text { po.jo. })_{\mathrm{FT}}<\mathrm{re}>\right)_{\mathrm{Pw}}$

'canoe'

c. [ju iuha'setu]

yurujare-tu

$\left((\text { yu.ru. })_{\mathrm{FT}}(\text { ja.re. })_{\mathrm{FT}}<\mathrm{tu}>\right)_{\mathrm{Pw}}$

'We are Yurakaré'

In (1a), the disyllabic word mala receives stress on the first syllable as a result of the rule that word-final syllables, being extrametrical, cannot be stressed. The iambic nature of Yurakaré feet can be seen in (1b) and (1c). In (1b), pojore 'canoe', a threesyllable word, has stress on the second - or penultimate-syllable. Iambic foot construction begins at the left edge of the word, resulting in (w s) feet. The same holds for the four-syllable word in (1c), where stress falls on the antepenultimate syllable. Foot construction does not continue after the first foot in this word, since the final syllable is extrametrical. Example (2) shows that primary stress is placed on the rightmost marked syllable, and that this primary stress assignment has the phonological word as its domain, the top two lines referring to the levels of primary and secondary stress, based on the prosodic structure given in the bottom line.

(2)

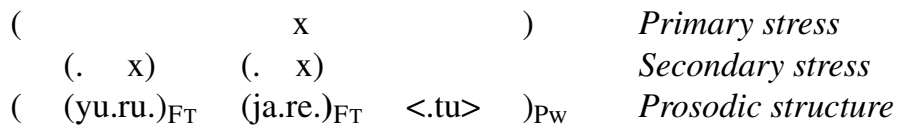

An additional prosodic constraint is weight sensitivity: heavy syllables (i.e. syllables with a coda) often receive primary or secondary stress, even if this goes against the general iambic pattern. ${ }^{6}$ This suggests that heavy syllables can form feet on their own, leaving the second syllable of trisyllabic words unfooted, indicated in (3).

a. ['bal:ata]

bállata

$\left((\text { bal. })_{\mathrm{FT}} \text { la. }<\mathrm{ta}>\right)_{\mathrm{Pw}}$

'cultivated plants, crops'

b. ['Jonkoto]

shónkoto

$\left((\text { shon. })_{\mathrm{Ft}} \text { ko. }<\mathrm{to}>\right)_{\mathrm{Pw}}$

'hole'

c. ['kuk:ulæ]

kúkkulë

$\left((\text { kuk. })_{\mathrm{FT}} \mathrm{ku} .<\mathrm{lë>}\right)_{\mathrm{Pw}}$

'plantation'

\footnotetext{
${ }^{6}$ Geminate consonants, as in ballata /'bal:ata/ and kukkulë /'kuk:ulæ/ are considered to be heterosyllabic. This is supported by the accent data but also for instance by allophonic variation of certain vowels dependent on whether they are followed by a coda consonant or not, e.g. /a/ changes to [a] in closed syllables, as is the case in [bal:ata].
} 
The basic parameter settings described here (iambic left-to-right rhythm, weight sensitivity, extrametricality, and rightmost stress) form the basis for accent placement in Yurakaré. However, there are additional rules that interfere with this general system, most of which are related to specific morphemes or roots. This will be discussed in further detail in the next sections.

\subsection{Rhythm, moras, feet, and affixes}

The first example of morphological interference with the prosodic system is the interaction between morphology and secondary stress, at the level of the foot. As mentioned above, the mapping rules for the lowest levels of the prosodic hierarchy-the syllable and the foot-are generally considered not to refer to morphological structure. This seems to be violated in Yurakaré.

A major intervening factor in the basic stress system of Yurakaré is that there are a number of prefixes that require (primary or secondary) stress. In the nominal domain, these are the plural possessive prefixes $t a$ - 'our', $p a$ - 'your (PL)' and $m a$ - 'their'. In the verbal domain these are all syllabic prefixes, except for $t i$ - ' $1 \mathrm{SG}$ object' and $m i$ '2SG object', and the aspectual prefixes $i$ - 'PERFECTIVE' and $a$ - 'IMPERFECTIVE'. The fact that they attract stress can be shown by a contrastive example in the nominal domain, given in (4). The proposed prosodic structure, assuming that the stressattracting prefixes can form feet on their own is also given, and addressed more fully below.
a. [ti'sibæ]
standard rhythm
ti-sibë
$\left((\text { ti.si. })_{\mathrm{FT}}<\mathrm{bë>}\right)_{\mathrm{Pw}}$
'my house'
b. ['tasibæ]
stress-attracting prefix
tá-sibë
$\left((\text { ta. })_{\mathrm{FT}} \text { si. }<\mathrm{bë>}\right)_{\mathrm{Pw}}$
'our house'

In (4a) the normal iambic pattern is maintained, but in (4b) this pattern is overruled by the stress-attracting prefix $t a-$. If a word is longer than three syllables, normal foot structure regulates the stress placement, the marked prefix gets secondary stress, and primary stress shifts according to the basic rhythmic pattern (iambic, left-to-right). This suggests that these stress-attracting prefixes form feet on their own.
a. [ti'pohore]
standard rhythm
ti-pójore
$\left((\text { ti.po. })_{\mathrm{FT}} \text { jo. }<\mathrm{re}>\right)_{\mathrm{Pw}}$
'my canoe'
b. [tapo'hoie]
ta-pojore
$\left((\text { ta. })_{\mathrm{FT}}(\text { po.jo. })_{\mathrm{FT}}<\mathrm{re}>\right)_{\mathrm{PW}}$
'our canoe'
stress-attracting prefix 
In addition to stress-attracting prefixes, though an uncommon pattern, there are also stress-attracting syllables within roots, as is the case with the first syllable of bata 'to get going'?
a. [, mila'bataj]
mi-la-bata-y
'I am leaving you.'
b. [ka'bataj]
ka-bata-y
'I am taking it with me.'

The expected iambic pattern of (6a) would be *milábatay, as indeed is observed in other verbs that take the prefix combination mi-la-, like milámalay 'I left you'. Instead, the primary stress is on the first syllable of the root. Likewise, (6b) goes against the expected accent pattern. $\mathrm{Ka}$ - is a stress-attracting prefix (as can for instance be seen in kámala 'I took it'). Nevertheless, it does not receive any stress when combined with the root bata. We have to assume that the first syllable of bata is stressattracting, thus allowing for maintaining the general prosodic patterns and explaining the behaviour of bata across contexts. In fact, in the case of bata there is a historical reason for the deviant prosodic behaviour. Bata (as well as other verbs ending in $-t a$ ) historically derives from an ideophone-verb construction, in which the verb ta 'say' combined with a directly preceding ideophone (cf. Van Gijn 2010). Ideophones have deviant prosodic characteristics, one of them being that they often have a stressed final syllable. Ideophones can furthermore - unlike other word classes-be realized as monosyllabic items. Roots with deviant prosodic behaviour are usually of this type (i.e. ending in $-t a$ ) although not all verbs that diachronically derive from ideophones show this behaviour. It seems reasonable to assume that there is a grammaticalization process involving 'normalization' of the stress pattern in some of these roots.

A final piece of the puzzle that should be mentioned here is that the stressattracting prefixes behave exactly like closed syllables in terms of rhythm and stress. If two closed syllables are adjacent, to avoid stress clash, rather than assigning secondary stress to both, only one of them is stressed, favouring the iambic pattern.

$$
\begin{array}{ll}
\text { a. } & \text { [nih'tafta] } \\
& \text { nijtashta } \\
& \left((\text { nij.tash. })_{\mathrm{FT}}<\mathrm{ta}>\right)_{\mathrm{Pw}} \\
& \text { 'It won't be there.' } \\
\text { b. } \quad \text { [si'b:æy:u] } & \text { sibbënñu } \\
& \left((\text { sib.bëñ. })_{\mathrm{FT}}<\tilde{n} u>\right)_{\mathrm{Pw}} \\
& \text { 'little house' }
\end{array}
$$

\footnotetext{
${ }^{7}$ Different analyses of foot structure are possible. Either the syllable $b a$ forms a foot of its own and refooting takes place to the left of it in a trochaic rhythm from right to left (reversing the standard procedure): ((mi.la)(ba)<tay $>$ ), or $b a$ forms the head of a foot, taking the preceding syllable as its dependent: $((\mathrm{mi})(\mathrm{laba})<\mathrm{tay}>)$.
} 
c. [bom'bombo]

bombombo

$\left((\text { bom.bom. })_{\mathrm{FT}}<\mathrm{bo}>\right)_{\mathrm{PW}}$

'clouded'

Likewise, if a stress-attracting prefix or syllable is followed by a closed syllable, stress follows an iambic pattern (8). The same is true for sequences of two stressattracting prefixes and a sequence of a heavy syllable and a stress-attracting syllable (9).

a. [ta'bujta]

ta-buyta

$\left((\text { ta.buy. })_{\mathrm{FT}}<\mathrm{ta}>\right)_{\mathrm{Pw}}$

'our chief'

b. [ta'huk:ulæ]

ta-júkkulë

$\left((\text { ta.juk. })_{\mathrm{FT}} \mathrm{ku} .<\mathrm{lë>}>\right)_{\mathrm{Pw}}$

'our plantation'

(9) a. [ta'bata]

ta-báta

$\left((\text { ta.ba. })_{\mathrm{FT}}<\mathrm{ta}>\right)_{\mathrm{PW}}$

'He is taking us.'

b. [mim'bata]

mi-m-báta

$\left((\text { mim.ba. })_{\mathrm{FT}}<\mathrm{ta}>\right)_{\mathrm{PW}}$

'He is moving towards you.'

I come back to possible ways to analyse these facts within the restrictions of the Prosodic Hierarchy below in Sect. 4.

\subsection{Minimality constraints and root types}

A second area where morphological interference with the prosodic component becomes apparent is in the parsing of material into feet within the domain of the p-word. Generally speaking, phonological material is parsed into feet wherever possible, but not at all costs. This is in itself not a special characteristic of Yurakaré, but the negotiations between the different levels are not uniform across root types, which once again highlights the intimate connection between phonological, grammatical, and semantic information in this language. ${ }^{8}$

If we keep in mind the extrametrical final syllable, it seems that Yurakare goes to some lengths to ensure that the p-word (excluding the extrametrical final syllable)

\footnotetext{
${ }^{8}$ This type of morphological interference does in fact not go against any predictions of the Prosodic Hierarchy, it is simply a further example of how morphology and prosody interact in Yurakaré.
} 
is parsed into feet, as can be seen in (10), which displays a pattern found only with some monosyllabic roots. ${ }^{9}$

\begin{tabular}{|c|c|c|c|}
\hline a. [ti'paa] & ti-paa & $\left((\text { ti.pa. })_{\mathrm{FT}}<\mathrm{a}>\right)_{\mathrm{PW}}$ & 'my brother' \\
\hline ['tapa] & ta-pa & $\left((\text { ta. })_{\mathrm{FT}}<\mathrm{pa}>\right)_{\mathrm{Pw}}$ & 'our brother' \\
\hline [ti'piì] & ti-püü & $\left((\text { ti.pü. })_{\mathrm{FT}}<\ddot{u}>\right)_{\mathrm{PW}}$ & 'my road' \\
\hline ['tapi] & ta-pü & $\left((\mathrm{ta} .)_{\mathrm{FT}}<\mathrm{pü}>\right)_{\mathrm{PW}}$ & 'our road' \\
\hline [ti'too] & ti-too & $\left((\text { ti.to. })_{\mathrm{FT}}<\mathrm{O}>\right)_{\mathrm{PW}}$ & 'my bone' \\
\hline ['tato] & ta-to & $\left((\text { ta. })_{\mathrm{FT}}<\text { to }>\right)_{\mathrm{PW}}$ & ‘our bone' \\
\hline
\end{tabular}

In each of the examples in (10), the prefix $t i$ - 'my' which cannot form a foot on its own triggers doubling of the root vowel, creating a trisyllabic structure. The prefix ta-, which can form a foot on its own, does not trigger vowel doubling. An explanation of these patterns is based on the points made above that (i) syllables are iambic, constructed from left to right, and (ii) the final syllable is extrametrical. If avoidance of degenerate feet is obeyed, a word needs at least two moras for the construction of an iambic foot, plus another syllable which is extrametrical. This means either three light syllables, or a heavy syllable (i.e. closed or consisting of a stress In other words: the minimal p-word in Yurakaré consists of a foot plus an extrametrical final syllable.

Not all monosyllabic roots seem to behave in the same way, however, as can be seen in (11), which displays a minority pattern (for reasons of exposition, the geminate consonants in the phonetic transcriptions are doubled).
a.
['tin:u $\mathrm{tanu}]$
ti-nñu
$\left((\text { tiñ. })_{\mathrm{FT}}<\tilde{\mathrm{n} u}>\right)_{\mathrm{PW}}$
'my child'
ta-ñu
$\left((\text { ta. })_{\mathrm{FT}}<\tilde{n} u>\right)_{\mathrm{PW}}$
'our child'
b. ['tib:a] ti-bba
$\left((\text { tib. })_{\mathrm{FT}}<\mathrm{ba}>\right)_{\mathrm{PW}}$
'my husband'
['taba]
ta-ba
$\left((\text { ta. })_{\mathrm{FT}}<\mathrm{ba}>\right)_{\mathrm{PW}}$
'our husband'

In (11) the root vowel is not doubled when combined with a $t i$ - prefix, but the root consonant is, creating a closed syllable, which can function as a foot.

Similar patterns to the one in (11) are found for many roots with an underlying CVCV pattern, which do not satisfy the minimal p-word requirement either. A widespread pattern for Yurakaré nouns with the underlying structure CVCV is to geminate the intervocalic consonant when no morphological material is added, creating a closed first syllable and an acceptable foot structure. This process is shown in (12).
a.
[ti'doho $\mathrm{tiho}]$
dojjo
$\left((\text { doj. })_{\mathrm{FT}}<\mathrm{jo}>\right)_{\mathrm{PW}}$
'body'
[ti'doho] ti-dojo
$\left((\text { ti.do. })_{\mathrm{FT}}<\mathrm{jo}>\right)_{\mathrm{PW}}$
'my body'
b. ['sam.ma]
samma
$\left((\text { sam. })_{\mathrm{FT}}<\mathrm{ma}>\right)_{\mathrm{PW}}$
'water'
[ti'sama] ti-sama
((ti.sa.) $\left.)_{\mathrm{FT}}<\mathrm{ma}>\right)_{\mathrm{PW}}$
'my water'
c. ['yow.wo] ñowwo
$\left((\text { ñow. })_{\mathrm{FT}}<W 0>\right)_{\mathrm{PW}}$
'manioc'
[ti'nowo] ti-ñowo
$\left((\text { ti.ño. })_{\mathrm{FT}}<\mathrm{WO}>\right)_{\mathrm{PW}}$
'my manioc'

\footnotetext{
${ }^{9}$ Apparent counterexamples, such as the one in (1a) above, can be accounted for by making reference to the lexical class of the word. I come back to this below.
} 
There are a few exceptions among the nouns, a number of them loanwords from Spanish, but the pattern in (12) is by far the most frequent one. The picture that emerges from these data is that (i) it is important that material is parsed into feet and (ii) feet need to be well-formed, i.e. bimoraic. ${ }^{10}$

However, the pattern seems to be restricted to nouns, judging from the apparently well-formed p-words in (13).

$\begin{array}{lll}\text { ['mala] } & \text { mala } & \left((\text { ma. })_{\mathrm{FT}}<\mathrm{la}>\right)_{\mathrm{Pw}} \\ \text { ['tuwi] } & \text { tuwi } & \left((\text { tu. })_{\mathrm{FT}}<\mathrm{wi}>\right)_{\mathrm{Pw}} \\ \text { ['toto] } & \text { toto } & \left((\text { to. })_{\mathrm{FT}}<\text { to }>\right)_{\mathrm{Pw}} \\ \text { ['nama] } & \text { nama } & \left((\text { na. })_{\mathrm{FT}}<\mathrm{ma}>\right)_{\mathrm{Pw}} \\ \text { ['daja] } & \text { daja } & \left((\text { da. })_{\mathrm{FT}}<\mathrm{ja}>\right)_{\mathrm{Pw}} \\ \text { ['dele] } & \text { dele } & \left((\text { de. })_{\mathrm{FT}}<\mathrm{le}>\right)_{\mathrm{Pw}}\end{array}$

'He went.'
'He died.'
'He shook it.'
'(It is) dry.'
'It hangs.'
'He fell.'

The gemination pattern of (12) is completely absent in non-nouns. This means that Yurakaré does not seem to allow for degenerate feet for nominal roots, whereas it does for the rest of the lexicon.

Nevertheless, it seems true both for nominal and non-nominal roots that-leaving aside the extrametrical final syllable-Yurakare shows some syncope patterns from which it appears that phonological material not parsed into feet is avoided. There does, however, still seem to be a difference between nominal and non-nominal roots in this respect again, but it is more gradual.

Words with four syllables normally have a stressed antepenultimate syllable, and an unstressed penultimate syllable. The latter is often elided, sometimes optionally, sometimes obligatorily. This can be connected to the fact that these syllables are unfooted. Apparently, Yurakaré has a (low-level) tendency to avoid these unfooted syllables. The elision processes are indicated in (14), optionality is represented by giving alternatives separated by ' $\sim$ '.

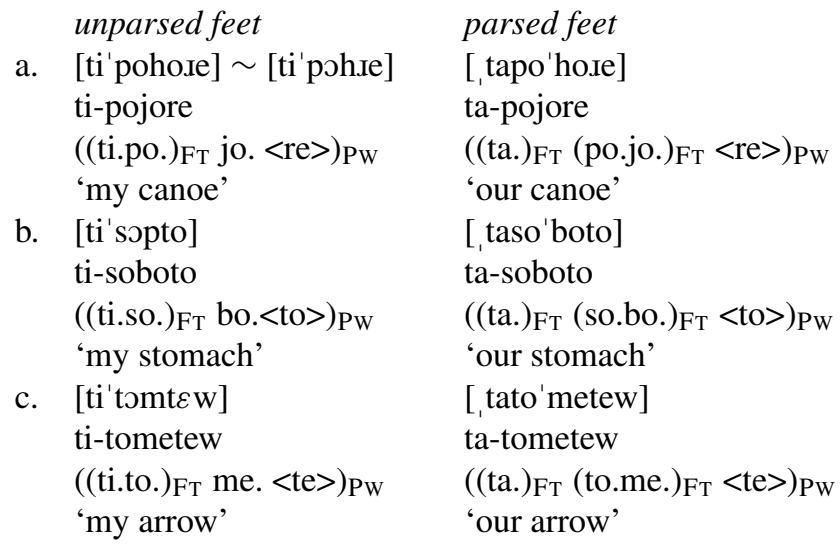

\footnotetext{
${ }^{10}$ In terms of minimality constraints Yurakare seems to make the following compromise: in order to avoid degenerate feet material may be added to the input but only up to a certain limit. It seems that only one extra segment can be added, not more. So the citation form of words like 'road' and 'bone' is pü.ü and to.o, respectively, not pü.ü.ü or to.o.o.
} 
The situation is slightly different for words with three syllables. In some cases, the same process applies, when the prosodic structure results in an unfooted second syllable shown in (15), where the roots are prefixed with a stress attracting marker. ${ }^{11}$

$\begin{array}{llll}\text { ['tap:æ] } & \text { ta-ppë } & \left((\text { ta. })_{\text {FT }} \text { pë. }<\text { pë }>\right)_{\mathrm{Pw}} & \text { 'our grandfather' } \\ \text { ['tam:e] } & \text { ta-mme } & \left((\text { ta. })_{\mathrm{FT}} \text { me. }<\mathrm{me}>\right)_{\mathrm{Pw}} & \text { 'our mother' } \\ \text { ['tap:i] } & \text { ta-ppi } & \left((\mathrm{ta})_{\mathrm{FT}} \mathrm{pi}<\mathrm{pi}>\right)_{\mathrm{Pw}} & \text { 'our younger brother' }\end{array}$

However, for some roots, like the ones in (16) having an unfooted syllable does not lead to elision.

$$
\begin{array}{llll}
\text { ['tadoho] } & \text { tá-dojo } & \left((\text { ta. })_{\mathrm{FT}} \text { do. }<\text { jo }>\right)_{\mathrm{Pw}} & \text { 'our body' } \\
\text { ['tasama] } & \text { tá-sama } & \left((\mathrm{ta} .)_{\mathrm{FT}} \text { sa. }<\mathrm{ma}>\right)_{\mathrm{Pw}} & \text { 'our water' } \\
\text { ['tajowo] } & \text { tá-ñowo } & \left((\mathrm{ta} .)_{\mathrm{FT}} \text { ño. }<\mathrm{wo}>\right)_{\mathrm{Pw}} & \text { 'our manioc' }
\end{array}
$$

For nominal roots, the first syllable only seems to be deleted when it is identical to the second and perhaps also only with very frequent nouns.

Non-nominal disyllabic roots seem slightly more tolerant to deletion, as is shown in (17), where syllable or vowel deletion takes place even if the root syllables are not identical, sometimes leading to further assimilation processes, as in (17b).
a. ['kat:a]
ka-tta
$\left((\text { ka. })_{\mathrm{FT}} \text { tü. }<\mathrm{ta}>\right)_{\mathrm{PW}}$
'Put it [there].'
b. ['lis:æ]
li-ssë
((li.) $)_{\mathrm{FT}}$ të.<së>) $)_{\mathrm{PW}}$
'It sticks in there.'
c. ['kamla] ka-mla
$\left((\mathrm{ka} .)_{\mathrm{FT}} \mathrm{ma} .<\mathrm{la}>\right)_{\mathrm{Pw}}$
'bring it/take it.'

The difference between (15) and (16) on the one hand and (17) on the other seems to be a further indication of the nominal versus non-nominal split in Yurakaré, and the extensive influence of morphosyntax on the behaviour of the p-word in the language. It must be said, however, that the differential treatment of unfooted material is a more gradual difference between nominal and non-nominal roots, since there are disyllabic verbal roots that do not allow for elision.

\subsection{Primary stress, intonation, and clitics}

Although the conditions and domains for intonational patterns in Yurakaré require further study, it seems that there are three possible situations for intonation peak placement, and how this relates to primary word stress.

(i) The intonation peak coincides with a primary stress position of a p-word.

(ii) The intonation peak falls on the penultimate syllable of a p-word (plus enclitics), regardless of its stress pattern.

(iii) The intonation peak falls on the final syllable of a p-word (plus enclitics).

Situation (iii) sheds light on the question why the final syllable of a p-word is extrametrical, which is functionally motivated: in certain pragmatic circumstances wordfinal syllables can be accented. This is arguably not word stress, but rather intonational or utterance accent. There are at least three domains in which the Intonational

\footnotetext{
${ }^{11}$ With a singular (non-stress-attracting) prefix, as in the examples in (14), the middle vowel is protected against elision: [ti'pæpæ], [ti'meme], [ta'pipi].
} 
Phrase can require final accentuation (although it is not obligatory): temporal background clauses, imperatives, and addressees. The former domain ends with a morphologically attached subordinator, which can be accented to indicate that a pivotal moment in the story has been reached, so that the hearer knows that she must pay extra attention, to paraphrase the words of a speaker. Imperative forms and addressees may also have accent on the final syllable, which has the same effect of eliciting focused attention from the addressee, as in the following example. ${ }^{12}$

['amt $\int \mathrm{i}$ 'batam aj'sa]
$\left(\left((\mathrm{am} .)_{\mathrm{FT}}<\mathrm{chi}>\right)_{\mathrm{Pw}}\left((\mathrm{ba} .)_{\mathrm{FT}}<\operatorname{tam}>\right)_{\mathrm{Pw}}\left((\mathrm{ay})_{\mathrm{FT}}<\mathrm{sa}>\right)_{\mathrm{PW}}\right)_{\mathrm{IP}}$
$\mathrm{am}=\mathrm{chi} \quad$ bata-m Aysá?
$\mathrm{WH}=\mathrm{DIR}$ go.INT Aysa
'Where are you going, Aysa?'

Whereas normal stress is on the penultimate, heavy syllable ['ajsa] in the context of (18) accent may move to the final syllable [aj'sa]. ${ }^{13}$ Since extrametricality for purposes of p-word-level stress is absolute, across the lexicon, final accent is very salient.

This means that, in a way, the pragmatic component of the language has an influence on the structure of the p-word by reserving final syllables for the intonation pattern exemplified in (18). This is, of course, not the same as saying that, in terms of mapping rules, the p-word needs access to the pragmatic component. The functionality or the exploitation of the final syllable of p-words is not required knowledge for the construction of well-formed p-words. A general statement to the effect of simply ignoring the final syllable in the domain for metric purposes is enough. Nevertheless, it indicates a connection between the different levels.

The difference between situations (i) and (ii) reveals another interesting contrast, between different types of clitics. In terms of their distribution, there are two types of clitics ${ }^{14}$ in Yurakaré: phrasal clitics and floating clitics. Phrasal enclitics are restricted to those markers that attach to the end of the nominal constituent: the plural marker and postpositional markers to the right; phrasal proclitics are articles/reduced demonstratives that attach to the left edge. They share this position with their unreduced counterparts, making them simple clitics. ${ }^{15}$ Floating clitics (see Aikhenvald 2002:46) do not have a fixed position, but are rather found in several positions in the clause, with the ability to attach to hosts of several lexical classes. The position of floating clitics mainly seems to be determined by focus.

In order to understand the prosodic behaviour of enclitics, it is important to first consider the prototypical behaviour of suffixes in Yurakaré, which is that they simply

\footnotetext{
${ }^{12}$ Abbreviations used in this paper: CMT commitment; DIR 'direction'; INT 'intentional'; MDG medial degree; MOM momentaneous; PL plural; POSS possessive; SG singular; WH 'question word'.

${ }^{13}$ It is difficult to ascertain whether the intonational accent is added to the existing lexical stress pattern or whether it replaces it. Relatively, however, the final syllable is much more salient than the others.

${ }^{14}$ Clitics are defined here as elements that are prosodically dependent (i.e. they do not project their own p-word) and distributionally more free than affixes (i.e. they have less selection restrictions).

${ }^{15}$ By simple proclitics I mean, following Zwicky 1977, weak (prosodically dependent) forms whose distribution is identical to (a subset of) the distribution of their prosodically independent counterparts.
} 
extend the domain for rhythm and stress (provided they have at least one syllable) according to the metrical rules of the language: ${ }^{16}$

a. [, ot:o'mafitu]

((ot.) (to.ma.) shi <tu>)

otto-mashi-tu

go.out-MDG-1PL.S

'We went out a little.'

b. [ti,poho'seni]

((ti.po.) (jo.re.) <ni>)

ti-pojore-ni

1SG.POSS-canoe-INT

'my future canoe/my canoe-to-be'

Phrasal enclitics behave metrically like suffixes (although distributionally they do not, since they may attach to different types of hosts, as long as it is the last word of the nominal constituent), including the fact that they share syncope patterns of unfooted material discussed above.

a. [ti'sipt $\left.\int \mathrm{i}\right]$

(ti.si.) bë. <chi>

ti-sip $=$ chi

1SG.POSS-house $=$ DIR

'to my house'

b. [tasi'bæt $[\mathrm{i}]$

(ta.)(si.bë.)<chi>

ta-sibë $=$ chi

1PL.POSS-house $=$ DIR

'to our house'

The floating clitics, however, do not seem to interfere with the metrical system, as exemplified for the floating clitics $=l a$ (speaker commitment) and $=b \ddot{e}$ (momentaneous). The proposed prosodic structure up to the $\mathrm{p}$-word is also given.

$$
\begin{aligned}
\text { a. } & \text { ['tin:ula] } \\
& \left((\text { tiñ. })_{\mathrm{Ft}}<\tilde{\text { nu. }}>\right)_{\mathrm{Pw}} \text { la } \\
& \text { ti-ñu=la } \\
& \text { 1 sG-child=CMT } \\
\text { b. } \quad & {[\text { 'sam:abæ] }} \\
& \left((\text { sam. })_{\mathrm{Ft}}<\mathrm{ma} .>\right)_{\mathrm{Pw}} \text { bæ } \\
& \text { samma=bë } \\
& \text { water=MOM }
\end{aligned}
$$

In the examples of (21), it is shown that the gemination of the root consonant is still present, in spite of the fact that the addition of the enclitic would create the possibility

\footnotetext{
${ }^{16}$ It must be said that the metrical behaviour of clitics is not entirely understood yet, due to the complex interaction with higher-level (intonational) accentuation. However, phrasal enclitics can be contrasted with other types of clitics in the sense that the former are never ignored by word-level accent.
} 
of forming a foot to its left. In other words: floating clitics seem to be ignored by the rules of prosodically conditioned gemination.

Although floating clitics do not form part of the domain of lexical stress, they do seem to form part of the domain for intonation. Penultimate intonation (situation ii) may cause the main accent to be on an unexpected syllable from the perspective of word stress. The floating clitics do seem to at least potentially count when it comes to the position of penultimate intonation, judging from pairs like the one in (22).
a. ['nihtala]
yokkoshe nijtala
truly not.be=CMT
'Aren't there really any?'
b. [nih'tala]
nijta=la
not.be $=\mathrm{CMT}$
'There aren't any!'

With respect to the exceptional intonation pattern in Yurakare where the peak lies on the final syllable of a word, floating clitics can have a final-syllable peak, which is another indication that they do form part of the intonational phrase.
a. [am:a'bæ]
amma=bë
come.IMP $=$ MOM
'Come here for a while!'
b. $\quad($

(* $\quad$ primary stress
(*) $\quad$ secondary stress
$\left(\left((\mathrm{am} .)_{\mathrm{FT}}<\mathrm{ma} .>\right)_{\mathrm{PW}} \text { bë }\right)_{\mathrm{IP}}$

Summarizing, floating clitics, unlike phrasal clitics, do not interact with lexical stress, but they do seem to be part of the domain for intonation.

The domain for word stress does not include simple proclitics either. Demonstrative pronouns in Yurakaré have unstressed counterparts:

\begin{tabular}{|c|c|}
\hline Demonstratives i & karé \\
\hline independent form & proclitic form \\
\hline ana ['ana] & an [an] \\
\hline ati ['ati] & at [at] \\
\hline naa ['naa] & na [na] \\
\hline
\end{tabular}

The proclitic forms are phrasal clitics in that they attach to the leftmost element of the noun phrase when functioning attributively. ${ }^{17}$

\footnotetext{
${ }^{17}$ One of the proclitics ( $\left.a n=\right)$ does interact with its host in terms of assimilation of nasals to the place of articulation of a following consonant, a process that is attested between prefixes and roots and between roots and suffixes but not between words.
} 
Table 3 Clitic types and word stress in Yurakaré

\begin{tabular}{lll}
\hline & Clitic type & Interact with stress \\
\hline Phrasal enclitics & Special & Yes \\
Phrasal proclitics & Simple & No \\
Floating enclitics & Special & No \\
\hline
\end{tabular}

Concluding, the prosodic behaviour of clitics in Yurakaré depends very much on the type of clitic (as shown in Table 3). It is not possible to draw a distinctive line on the basis of familiar typological characteristics of clitics: not between phrasal and floating clitics, not between enclitics and proclitics, and not between simple and special clitics.

\section{Discussion}

Phonological words in Yurakaré are most reliably recognizable by their stress pattern. P-words in Yurakaré have one syllable that carries primary stress. There are a few other phonological rules that mainly operate at the level of the p-word, like lenition of $/ \mathrm{k} /$ to [h] after a vowel, place assimilation of nasals before stops (though there is one proclitic that also takes part in this process), but these are only applicable in a subset of cases.

The p-word domain is characterized as the domain for primary stress (end stress rule), second-layer secondary stress (the iambic rhythm pattern and the avoidance of stress clash) and an extrametrical final syllable. P-words minimally consist of a single g-word, but may also contain more than one g-word (where one of the elements is a phrasal clitic).

However, although these characteristics describe the general contours of the $\mathrm{p}$ word in Yurakaré, other characteristics show a less coherent picture. There are four factors that present examples of interference from non-phonological domains.

- There are a number of prefixes that behave like bimoraic (closed) syllables, even if they have a CV structure. This is evidence of morphological interference at the level of the foot.

- There are two types of roots: nominal and non-nominal. The former do not allow for degenerate feet at the left edge of the p-word, the latter do, suggesting minimality requirements for only part of the lexicon. There also seems to be a more gradual difference between these two types of roots in the extent to which they allow for the deletion of unfooted material, where nominal roots seem to preserve unfooted material more often than non-nominal roots in trisyllabic p-words.

- There are three types of clitics: floating clitics that do not participate in word stress, phrasal proclitics that do not participate either, and phrasal enclitics that do, highlighting a non-straightforward interaction between the p-word and the syntactic component.

- There is a strict extrametricality requirement for the final syllable, not just for primary stress, but also for secondary stress. It is, however, available for special intonational prominence. 
Starting with the first observation, the stress-attracting prefixes raise the question how they should be analysed in terms of prosodic constituency and mapping rules. One way of dealing with these prefixes is to consider them as non-cohering: rather than forming a p-word together with their morphological host, they form p-words of their own. This analysis seems unlikely because there are so many prosodic interactions between the prefixes and the bases they attach to, like rhythm patterns built from left to right, avoidance of stress clash with adjacent heavy or stress-attracting morphemes, and the end stress rule. Moreover, in that analysis they would constitute an exception to the rule that $\mathrm{p}$-words have an extrametrical final syllable. Related problems arise for analyses involving recursive $\mathrm{p}$-word structures, for which one would have to posit different rules at different levels.

Another route would be to consider the prefixes part of a higher constituent, either the Clitic Group (Nespor and Vogel 1986; Vogel 1990, 2009) or the Phonological Phrase. This route does not seem to be very promising either. It would mean that the Clitic Group would entail combinations of prefixes and bases, and no clitics (phrasal enclitics would form part of the p-word, other clitics of a higher structure) or that the Phonological Phrase would form a combination of two morphologically defined units and would have no mapping relation with syntactic structure (even though the p-word would because of the phrasal enclitics).

It seems most logical, then, to consider any string of affix + root combinations (as well as phrasal enclitics) as phonological words, with the addition that some morphemes carry specific prosodic information with them. These morpheme-specific phonologies are perhaps most efficiently handled by regarding them as dominant cophonologies (see e.g. Inkelas 1998). This would entail that the mapping relations in Yurakaré involve reference to morphological structure at prosodic levels below the p-word, assuming that first level accentuation is a foot-based rule in Yurakaré.

Different phonologies also have to be assumed for nominal and non-nominal roots in order to account for the minimality effects, and further morpheme-based phonologies have to be assumed for the different types of minimality effects of underlyingly monosyllabic nominal roots (vowel doubling versus consonant doubling). In general terms, this means that there are two types of p-words in Yurakaré: one for nominal roots, that requires at least three moras, and one for the rest, which allow for bimoraic words or, perhaps more accurate, which resist the addition of phonetic material to satisfy the three-mora minimality constraint. Like was the case with the prefixes, these differences could be handled by making reference to co-phonologies for nominal roots.

The prosodic behaviour of clitics shows that there is an interaction between the syntactic component and the p-word in the sense that the prosodic component requires access to distributional information of the clitics (whether phrasal or floating, whether enclitic or proclitic_-or whether simple or special) in order for the prosodic rules to apply correctly. Alternatively, and perhaps more efficiently, we could again make reference to co-phonologies for different types of clitics- the default for clitics being not to be part of the p-word, the phrasal enclitics being the exception.

If we take Selkirk's four possible prosodic sites for function words as possible analyses_-given in (25) for the clitics in Yurakaré (focusing only on metrical evidence) - the phrasal enclitics are analysed as structure (25b), the simple phrasal 
Fig. 2 Mapping rules for the p-word and lower constituents in Yurakaré

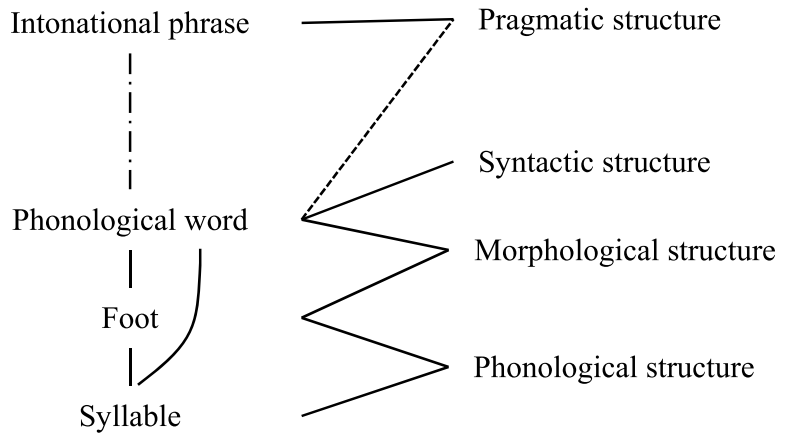

proclitics and the floating enclitics as (25d), i.e. the proclitics and floating clitics seem to attach directly to a higher constituent than the p-word.

Selkirk's (1996) prosodic sites for function words
a. $[[$ func $] \omega[$ lex $] \omega] \varphi$
b. $[[$ func + lex $] \omega] \varphi$
c. $[[$ func $] \sigma[$ lex $] \omega] \omega] \varphi$
d. $\quad[[$ func $] \sigma[$ lex $] \omega] \varphi$

Extrametricality, finally, is a relatively common phenomenon, but from the point of view of the Prosodic Hierarchy not necessarily straightforward. In Yurakaré, it seems that the final syllable is excluded from p-word level prosody, but it seems to be included in the Intonational Phrase, as it is a landing site for the word-final intonation pattern. So it is unclear whether this final syllable should be analysed as attaching to the Intonational Phrase rather than being part of the p-word or, perhaps more likely, whether a special mapping rule excludes final syllables from consideration in rhythm and stress, which is the analysis I have chosen in the prosodic structures of the examples. These p-word-final syllables are not parsed into feet and therefore seem to attach directly to the p-word, as do some of the non-elided syllables that are not parsed into feet.

Taking the facts discussed above into consideration, we can say that the p-word in Yurakaré looks as in (26)

$$
\begin{aligned}
& \text { The p-word of Yurakaré } \\
& \text { prefixes-root-suffixes=phrasal enclitics }
\end{aligned}
$$

Taking this, and the above discussion into consideration, we end up with a modified picture of mapping relations given in Fig. 2 (the original was given above in Fig. 1). ${ }^{18}$

Whereas the construction of syllables can be done without making any reference to other modules than phonology (giving preference to $\mathrm{CV}$ structures in general, and with a preference for $\mathrm{CVC}$ over $\mathrm{CCV}$ ), foot structure is dependent on whether or not

\footnotetext{
${ }^{18}$ The connection between the phonological word and the intonation phrase is indicated with a dotted line because there may be levels in between these two.
} 
there are any diacritically marked prefixes, so at this point morphological structure comes in, below the level of the p-word. The p-word itself, apart from to phonological structure, must have access to morphological information, in particular root type (nominal versus non-nominal), but also to syntactic structure to be able to distinguish between phrasal enclitics, which form part of the p-word, and other types of clitics, which do not. The pragmatic interference is strictly speaking no real mapping; since extrametricality is exceptionless at the level of the p-word, the p-word needs no information from the pragmatic component. It is included here however-in dotted lines-because it adds to the general point that, since words can be (and often are) sentences in polysynthetic languages, they must be equipped to act as such, in our case by making available their last syllable for sentence-level prosodic structures such as intonation.

As can be seen in Fig. 2, the p-word in Yurakaré is a major junction where many different levels come together. One could hypothesize that this is what can be expected in (poly)synthetic languages, where different levels tend to converge on the level of the (grammatical) word anyway, so one would expect this to be echoed in mapping rules with prosodic structure (see also Van Gijn and Zúñiga, this volume).

Interestingly, similar characteristics to the ones described in this paper for $\mathrm{Yu}$ rakaré have been reported for other languages. These more general patterns may point towards very general principles, but it is beyond the scope of this paper to systematically review the commonalities and differences between languages with similar patterns. Although I will mention some similar patterns in other language, the focus will be on potential reasons in Yurakaré for its peculiarities.

Hildebrandt (2007) reports that Limbu (Sino-Tibetan, Nepal) prefixes are not part of the phonological word for some phonological rules, though they are for others (among them stress). Hyman (2008) shows that Bantu (Sub-Saharan Africa) prefixes are excluded from "phonological activity that originates in the stem". Bickel et al. (2007) report that Chintang (Sino-Tibetan, Nepal) prefixes are best regarded to project p-words of their own in some respects (e.g. glottal stop insertion to avoid V-initial p-words) but not in others (e.g. stress). However, these superficially similar phenomena are different from Yurakaré in that the prefixes in the other languages do not impose their phonologies onto the rest of the p-word.

Hyman (2008) discusses left-right asymmetries in general, and in Bantu languages in particular. One of the asymmetries mentioned by him is that dominant affixes are more likely to be suffixes than prefixes. The facts of Yurakare show the opposite pattern, but there may be good reasons for this. Given that the iambic rhythm of Yurakare p-words is constructed from left to right, dominant suffixes would impose a disruption of this construction that either needs to be anticipated or needs to be corrected retroactively. For this reason it might be hypothesized that construction direction of the iambic rhythm pattern in p-words (left to right) disfavours dominant suffixes. Dominant prefixes have more chance to survive because they do not involve the same amount of calculative effort.

Yurakaré is also not alone in having a lexicon split between nominal and verbal roots, although details again differ from language to language. Hildebrandt (2007), again for Limbu, reports differential prosodic behaviour for compounds involving 
nouns and verbs. And of course in English some nominal and verbal roots are stressed according to different rules, perhaps most visibly in pairs like the ones in (27).

$\begin{array}{ll}\text { Verb } & \text { Noun } \\ \text { con'vict } & \text { 'convict } \\ \text { in'crease } & \text { 'increase } \\ \text { up'set } & \text { 'upset } \\ \text { re'cord } & \text { 'record }\end{array}$

There may be functional pressure for maintaining the prosodic distinction especially between nominal and verbal roots in Yurakaré. The distinction between nominal and verbal roots in Yurakaré is rather weak in the sense that nominal roots can be used as predicates without any additional marking (though vice versa is not possible without additional marking). However it arose in the past, the different prosodic behaviour of nominal roots may be exploited to enhance the opposition in particular with verbs.

The behaviour of clitics can be connected to observations reported by Peperkamp (1997) in her study of Italian dialects. The same person clitics show different prosodic behaviour in contrastive variants of Italian.
a. vínne
Lucanian
b. vənní=llə
c. vine $=$ mí=llə
a. véndi
Standard Italian
b. véndi=lo
c. véndi=me=lo

These dialectal difference suggest diachronic changes in the prosodic status of the person clitics: whereas in Standard Italian they do not seem to be integrated into the p-word as they cause no stress shift, in Lucanian they do.

We could apply a similar hypothesis to the clitic data of Yurakaré: the different prosodic statuses of the different clitics represent different diachronic stages. The different types of clitics may even reveal likely and less likely diachronic paths. It seems reasonable to assume that promiscuous host selection is a hindering factor in phonological integration. The phrasal enclitics attach to the right of the NP, but only two types of host are possible as NP-final words: either nouns or adjectives, and adjective only rarely occur in that position. The phrasal proclitics attach to the left side of an NP, where there is much more variability in the first lexical element, which may either be a noun, a numeral or quantifier, a possessor pronoun, or an adjective. Moreover, they may attach to the left edge of a relative clause (which are nominalised structures). The promiscuity of floating clitics is self-explanatory.

A fourth fact that is a bit awkward from the perspective of the prosodic hierarchy is the extrametrical final syllable, which may be regarded as a standardised misalignment. As mentioned above, this has a functional explanation, because in this way the final syllable can be reserved for exceptional accentuation, to arouse the interest of the hearer. So although it comes at the cost of an extra mapping rule, it comes 
with the advantage of creating a salient position for sentence-level intonation. This is especially useful for polysynthetic languages where words may be, and often are, sentences as well.

\section{Conclusion}

In this paper I highlighted four characteristics of Yurakaré that have non-straightforward interactions with prosodic structure. Although they are not incompatible with a Prosodic Hierarchy analysis - to the extent that prosodic levels can be recognisedthey do form deviations from some of the standard assumptions. It may not be coincidental that these patterns arise as they do. I have tried to argue for both functional and structural reasons that may push certain sub-patterns in particular directions.

- Dominant prefixes impose their inherent prosodic structure onto the rhythmic patterns bases they attach to, but they also underlie prosodic patterns associated with the p-word. Because rhythm construction in Yurakaré is from left to right, dominant prefixes are less disruptive than dominant suffixes, and so the latter have less chance of 'surviving'.

- Nominal roots have different minimality constraints than other types of roots. Given the weak noun-verb distinction in Yurakaré, it may be functional to maintain the deviant prosodic behaviour of nominal roots, thus exploiting prosody for distinguishing lexical classes.

- Different types of clitics show different prosodic behaviour. This may point towards different grammaticalization paths, where clitics that have less selection restrictions are less likely to integrate fully into the prosodic word structure of their host.

- Extrametricality of the final syllable is maintained because it provides speaker and hearer with a highly salient position for intonation peaks. This is especially functional because given the polysynthetic structure of Yurakaré words can be, and often are, sentences and/or utterances at the same time.

These facts are consistent with the conclusions drawn in Bickel et al. (2009) and Schiering et al. (2010) that the p-word is an emergent structure resulting from recurring usage patterns mentioned at the beginning of the paper. Not only is the p-word emergent, but it is constantly renegotiated, resulting in substructures, exceptions, and variations in the structure of $\mathrm{p}$-words and their mapping rules.

\section{References}

Aikhenvald, A. Y. (2002). Typological parameters for the study of clitics, with special reference to Tariana. In R. M. W. Dixon \& A. Y. Aikhenvald (Eds.), Word: a cross-linguistic typology (pp. 42-78). Cambridge: Cambridge University Press.

Bickel, B., Banjade, G., Gaenszle, M., Lieven, E., Paudyal, N., Rai, I. P., Rai, M., Rai, N. K., \& Stoll, S. (2007). Free prefix ordering in Chintang. Language, 83(1), 43-73.

Bickel, B., Hildebrandt, K., \& Schiering, R. (2009). The distribution of phonological word domains: a probabilistic typology. In J. Grijzenhout \& B. Kabak (Eds.), Phonological domains: universals and deviations (pp. 47-75). Berlin: de Gruyter. 
Campbell, L. (1997). Historical linguistics: an introduction (2nd ed.). Edinburgh: Edinburgh University Press.

Dixon, R. M. W. (1977). Some phonological rules in Yidiny. Linguistic Inquiry, 8(1), 1-34.

van Gijn, R. (2005). Head marking and dependent marking of case relations in Yurakaré. In M. Amberber \& H. de Hoop (Eds.), Competition and variation in natural languages: the case for case (pp. 41-72). Oxford: Elsevier.

van Gijn, R. (2010). Middle voice and ideophones, a diachronic connection: the case of Yurakaré. Studies in Language, 34(2), 273-297.

van Gijn, R. (2011a). Pronominal affixes, the best of both worlds: the case of Yurakaré. Transactions of the Philological Society, 109, 41-58.

van Gijn, R. (2011b). Subjects and objects in Yurakaré: a semantic account. International Journal of American Linguistics, 77(4), 595-621.

van Gijn, R. (2011c). Grammatical and semantic integration in Yurakaré subordination. In R. van Gijn, K. Haude, \& P. Muysken (Eds.), Subordination in native South American languages (pp. 169-192). Amsterdam: Benjamins.

Greenberg, J. (1987). Language in the Americas. Stanford: Stanford University Press.

Hall, T. A., Hildebrandt, K. A., \& Bickel, B. (2008). Introduction: theory and typology of the word. Linguistics, 46(2), 183-192.

Hayes, B. (1995). Metrical stress theory: principles and case studies. Chicago: The University of Chicago Press.

Hildebrandt, K. (2007). Prosodic and grammatical domains in Limbu. Himalayan Linguistics, 8, 1-34.

Hyman, L. M. (2008). Directional asymmetries in the morphology and phonology of words, with special reference to Bantu. Linguistics, 46, 309-350.

Inkelas, S. (1998). The theoretical status of morphologically conditioned phonology: a case study of dominance effects. In G. Booij \& J. van Marle (Eds.), Yearbook of morphology 1997 (pp. 121-156). Dordrecht: Kluwer Academic.

McMahon, A., \& McMahon, R. (2005). Language classification by numbers. Oxford: Oxford University Press.

Nespor, M., \& Vogel, I. (1986). Prosodic phonology. Dordrecht: Foris.

Peperkamp, S. (1997). Prosodic words. The Hague: Holland Academic Graphics.

Revithiadou, A. (2011). The phonological word. In M. van Oostendorp, C. J. Ewen, E. Hume, \& K. Rice (Eds.), The Blackwell companion to phonology (pp. 1204-1227). Malden: Wiley-Blackwell.

Schiering, R., Bickel, B., \& Hildebrandt, K. A. (2010). The prosodic word is not universal, but emergent. Journal of Linguistics, 46, 657-709.

Selkirk, E. O. (1978). On prosodic structure and its relation to syntactic structure. In T. Fretheim (Ed.), Nordic Prosody II (pp. 111-140). Trondheim: TAPIR.

Selkirk, E. O. (1980). The role of prosodic categories in English word stress. Linguistic Inquiry, 11, 563605 .

Selkirk, E. O. (1996). The prosodic structure of function words. In J. L. Morgan \& K. Demuth (Eds.), Signal to syntax: bootstrapping from speech to grammar in early acquisition (pp. 187-213). Mahwah: Lawrence Erlbaum.

Suárez, J. (1974). Macro-Pano-Tacanan. International Journal of American Linguistics, 37(3), 137-154.

Swadesh, M. (1962). Akten des 34. Amerikanistenkongresses. Afinidades de las lenguas amerindias (pp. 729-738). Vienna: Fred Berger.

Vogel, I. (1990). The clitic group in prosodic phonology. In J. Mascaró \& M. Nespor (Eds.), Grammar in progress: GLOW essays for Henk van Riemsdijk (pp. 447-454). Dordrecht: Foris.

Vogel, I. (2009). The status of the Clitic Group. In Grijzenhout and Kabak (pp. 15-46).

Zwicky, A. M. (1977). On clitics. Bloomington: IULC. 